\title{
Systematic Desensitization for Treating Specific Phobia of Earthworms: An In
} Vivo Exposure Study

\author{
Martin Herdiansyah $^{\mathrm{a}}$ and Nathanael J. Sumampouw ${ }^{\mathrm{b} *}$ \\ ${ }^{a}$ Clinical Adult Magister-Profession, Faculty of Psychology, Universitas Indonesia, Depok, \\ Indonesia; ${ }^{b}$ Clinical Psychology Department, Faculty of Psychology, Universitas Indonesia, \\ Depok, Indonesia
}

*Corresponding Author:

Nathanael J. Sumampouw

Clinical Psychology Department

Faculty of Psychology, Universitas Indonesia

Jl. Lkr. Kampus Raya, Depok, Jawa Barat

Indonesia, 16424

Tel.: +62 217270004

Email address: nathanael.elnandus@ui.ac.id 


\section{Systematic Desensitization for Treating Specific Phobia of Earthworms: An In Vivo Exposure Study}

Systematic desensitization was used to overcome the earthworm phobia of a 20-yearold female who is a college student majoring in Linguistics. This treatment is important because she will conduct a Real Work Lecture (K2N) related to plantation activities. Her earthworm phobia is considered to interfere with her K2N activities. Systematic desensitization, a behavioral treatment with in vivo exposure technique, was selected to overcome the client's phobia. Treatment was conducted in six individual sessions within 10 days. A progressive relaxation technique was also performed at the beginning of each treatment session to provide a relaxing effect on the client before the treatment. Results were measured using the Scale of Subjective Units of Discomfort (SUDS). The SUDS score significantly decreased from 95 prior to the treatment to 30 after the treatment. The SUDS form was given to the client at the end of each session to determine changes in the scale after the treatment. Follow up was qualitatively conducted by interviewing the client 1 year after the implementation of the treatment. Follow up was qualitatively conducted by interviewing the client 1 year after the implementation of the treatment, and the client reported that she is still able to control her fear when she faces earthworms.

Keywords: systematic desensitization, specific phobia, progressive relaxation

\section{Introduction}

According to DSM IV-TR, specific phobia is described as excessive fear caused by specific objects or situations; examples of specific phobia are fear of flying, snakes, and heights (APA, 2000). Specific fears of animals, blood, height, and closed spaces are highly prevalent in the general population including children, adolescents, adults, and elderly people (Muris \& Merckelbach, 2012; Davis, Ollendick, \& Öst, 2012). Specific phobia tends to belong to a cluster of fears of a small number of objects or situations. Specific phobia is an anxiety disorder, that is, a fear for no apparent and irrational reason, and negatively affects everyday life (Kring, Johnson, Davioson, \& Neale, 2013). The development of specific phobia is not only influenced by certain traumas but also due to dissemination of information and learning from observation (Barlow, 2002).

The etiology of specific phobia is based on behavioralistic perspectives; that is, specific phobias are conditioned and developed responses after a frightening event and become continuous because of avoidance behavior. An illustration of specific phobia is the case of Little Albert in the study of John Watson. In this case, a classic conditioner occurs, and a little boy who is actually not afraid of mice develops his fear of mice after being confronted with rats repeatedly coupled with a loud voice (Kring, Johnson, Davison, Neale, 2013). In addition to classical conditioning theory, social learning theory proposed by Bandura can explain the occurrence of specific phobia. Individuals develop specific phobia from observing a particular model. In this case, the process of observational learning prevails (Hall, Linzey, Loehlin, Manosevitz, 1985). Specific phobia tends to start during childhood. For example, data from the National Comorbidity Survey Replication 
indicated that by the age of 12 years, $75 \%$ of children already developed the disorder and will suffer from a specific phobia during their lifetime (Kessler, Chiu, Demler, \& Walters, 2005)

Fear and specific phobia can be treated using different techniques. Traditional treatment of fear involves counter conditioning using systematic desensitization (King, Ollendick \& Gullone, 1990). A previous survey conducted by a therapist indicated that approximately $19 \%$ of treatments of fears and specific phobia involve cognitive restructuring with in vivo exposure, $15 \%$ involve cognitive restructuring without in vivo exposure, and $8 \%$ involve systematic desensitization without in vivo exposure (Silverman \& Kearney, 1992). Exposure to frightening stimuli and situations activates the fear memory network, while information discordant with the fear-provoking element in the memory network is made available and incorporated (Muris \& Merckelbach, 2012). The rationale for in vivo exposure is the same as when it is applied for other types of phobias. However, the rationale for applied relaxation method needs to be elaborated considering that authors (Kozak \& Montgomery, 1981) caution against methods, such as relaxation and systematic desensitization.

Both relaxation and systematic desensitization ultimately results in correction of the network and reduction of fear (Foa \& Kozak, 1986). Two principles, namely, habituation and extinction, form the foundation of in vivo exposure and underscore the importance of systematic exposure to the feared situation. The principle of habituation suggests that when a response is elicited repeatedly, the strength of the response decreases. Despite the well -developed evidence for phobia treatment, the number of individuals undergoing it remains relatively low (Barlow, 2002) because phobics may find exposure to their fear as very aversive and overwhelming (Scott \& Stradling, 1997; Zayfert, 2000).

Several studies related to specific phobias have obtained success in treatments using systematic desensitization and exposure therapy. For example, in the research conducted by Buchanan and Houlihan (2008) on a 20-year-old woman with earthworm phobia, treatment was conducted in seven sessions and combined with diaphragmatic breathing to provide a relaxing effect on the client while undergoing exposure therapy. Buchanan and Houlihan (2008) used the Scale of Subjective Units of Discomfort (SUDS) to determine the hierarchy of fear of the client and measure it at each session to evaluate the treatment progress and also employed the State Trait Anxiety Inventory (STAI) to determine the level of anxiety of the client and the Behavior Avoidance Test (BAT) to evaluate her extent of avoidance behavior. Previous studies and surveys reported that systematic desensitization using exposure therapy shows a high success rate when used to address specific phobias.

\section{Methods}

\section{Participant}

The client is a 21-year-old woman who majors in Linguistics in X University in Depok. She is the first child and has one brother. Since childhood, she lives with her father and mother. Her father works as a police officer of the Republic of Indonesia and her mother works as a Civil Servant in the police department. She will conduct a Real Work Lecture (K2N), where the activities to be performed are related to plantations. 
The client personally approached the authors to obtain treatment for her fear of earthworms because she was worried that her fear would interfere with her $\mathrm{K} 2 \mathrm{~N}$ activities. The client reported no other psychological disturbance. Her phobia against earthworms has begun 6 years ago when she was 15 years old. She once stepped on earthworms while walking on the edge of the lake near her home and immediately became hysterical. Since then, she has been a phobic against earthworms that even hearing the word earthworm already made her very uncomfortable. She has always tried to avoid activities that could make her in contact with earthworms. When she encounters earthworms, she feels dizzy and trembling and she runs and shouts.

The client's fear of earthworms is a type of specific phobia of animals. Given the symptoms, such as dizziness and trembling, encountered by the client when dealing with earthworms and that these symptoms persist for more than six months, the client was diagnosed to have specific phobia in accordance with the DSM-IV TR criteria. When dealing with earthworms, she experiences hysterics and becomes the center of social attention. This condition often makes her feel uncomfortable because it is considered irrational to be afraid of something that is not harmful. Although her fear does not interfere with her friends, it often makes her dependent on others when in a phobic situation.

The client overcomes her fear by avoiding activities related to earthworms. She always asks for help from friends and her brother when she faces earthworm. She also screams and runs when she sees an earthworm in their garden. She once tried to confront her fear, but she was still unable to control her fear when dealing with earthworm.

\section{Research Design}

This research adopted a single-case study design and measured the hierarchy of fear before and after the treatment. A form regarding hierarchy of fear was also given to the client at the end of each session to monitor her treatment progress.

\section{Measurement}

The SUDS scale, a self-report tool for anxiety measurement, was used to determine the level of fear of earthworms of the client. The scale ranges from 0 (indicating no anxiety at all) to 100 (indicating the most severe anxiety) (Wolpe, 1973). The scale was used to measure client anxiety level during an exposure session. Decreasing SUDS score becomes the basis for continuation or termination of the session to achieve the designed objectives (Buchanan \& Houlihan, 2008). The client was also interviewed to collect data about her fear. The client's phobia of earthworms has started since she was in junior high school and continues up to present. She always avoids and asks for help from other people when she saw earthworms. Based on the observations conducted to the client, she showed an expression of fear when hearing the word earthworm during the interview. She closed her ears, shouted, and shaked her head. Hence, the client was confirmed to have a phobia against earthworms and require further therapy.

\section{Procedure}

In the first treatment session, the client was informed of facts regarding her phobia to make her understand factors related to it and the resulting effects when she sees or even hears the word earthworm. She was asked to create a hierarchy of her fear by sorting it into three stages, with scores of 0,50, and 100. After obtaining the image of fear at that level, she was asked to create a 
hierarchy order in accordance with what she feels from the lowest to the highest. She has also been given an explanation regarding the function of this hierarchy and asked her expectations of the treatment that will be conducted. She has also obtained information about the targets to be achieved at the end of the session.

Table 1

Hierarchy of the Client's Fear of Earthworm

\begin{tabular}{|c|c|}
\hline Scale of Fear & Step of Fear \\
\hline 100 & Holding earthworms by hand with no tools \\
\hline 95 & Taking earthworms using a tool \\
\hline 90 & Touching the earthworm by hand with no tools \\
\hline 85 & Step on the earthworm without the use of footwear \\
\hline 78 & Touching earthworms by hand using tools \\
\hline 65 & Step on the earthworm by using footwear \\
\hline 60 & See earthworms worms in large numbers / clusters \\
\hline 55 & Looking at the earthworm abruptly from a short distance \\
\hline 50 & Looking at large size earthworms moving from a distance of $30 \mathrm{~cm}$ \\
\hline 48 & Looking at large earthworms moving from a distance of $40 \mathrm{~cm}$ \\
\hline 45 & Looking at large earthworms moving from a distance of $50 \mathrm{~cm}$ \\
\hline 42 & Looking at large earthworms move from 1 meter away \\
\hline 41 & Looking at large earthworms move from 2 meters away \\
\hline 40 & Looking at large earthworms move from 3 meters away \\
\hline 39 & Looking at large diameter earthworms from a distance of $30 \mathrm{~cm}$ \\
\hline 38 & Looking at a large silent earthworm from a distance of $40 \mathrm{~cm}$ \\
\hline 37 & Looking at a large silent earthworm from a distance of $50 \mathrm{~cm}$ \\
\hline 36 & Looking at a large silence earthworms from a distance of 1 meter \\
\hline 35 & Looking at a large silence earthworms from a distance of 2 meters \\
\hline 34 & Looking at a large silence earthworms from a distance of 3 meters \\
\hline 33 & Looking at small earthworms from a distance of $30 \mathrm{~cm}$ \\
\hline 32 & Looking at small earthworms from a distance of $40 \mathrm{~cm}$ \\
\hline 31 & Looking at small earthworms from a distance of $50 \mathrm{~cm}$ \\
\hline 30 & Looking at small earthworms from a distance of 1 meter \\
\hline 29 & Looking at small earthworms from a distance of 2 meters \\
\hline 28 & Looking at small earthworms from a distance of 3 meters \\
\hline 25 & Viewing earthworm videos \\
\hline 20 & View photos of earthworms \\
\hline 18 & Viewing images of earthworms \\
\hline 15 & Imagine earthworms \\
\hline 10 & Listening to the stories that describe earthworms \\
\hline 0 & Mention the word earthworm \\
\hline
\end{tabular}

At the beginning of the second session, the client was subjected to progressive relaxation to decrease her anxiety levels and provide calm and relaxing feeling to the client. Smith, Amutio, Anderson, \& Aria argued that a positive way of handling stress is the use of progressive relaxation, which is a form of intervention for reducing stress; this intervention consists of tense and relaxing exercises for muscles, ranging from the head to the foot, and focuses on differences in sensation when the position of shifts (Dolbier, \& Rush, 2012). The client was also motivated to maintain her determination for the following treatment process. When the exposure began, the client showed discomfort when faced with an earthworm. In this stage, another person was asked to mention the word earthworm. The client shouted in the third stage where the examiner read a story describing earthworms. After trying to relax, she said she would continue. The client was able to reach the 
session tackling the bottom four hierarchies, namely, see colorless or two-dimensional images of earthworms. At the end of the second session, the subject said that she was happy to be able to fight the fear that she had always avoided. The client was then informed of the plan for the next session. In the end of the second session, a SUDS form was given to the client, and she was asked to write down changes in the score in the hierarchy table.

\section{Table 2}

Item Hierarchy of the Client's Fear of Earthworms

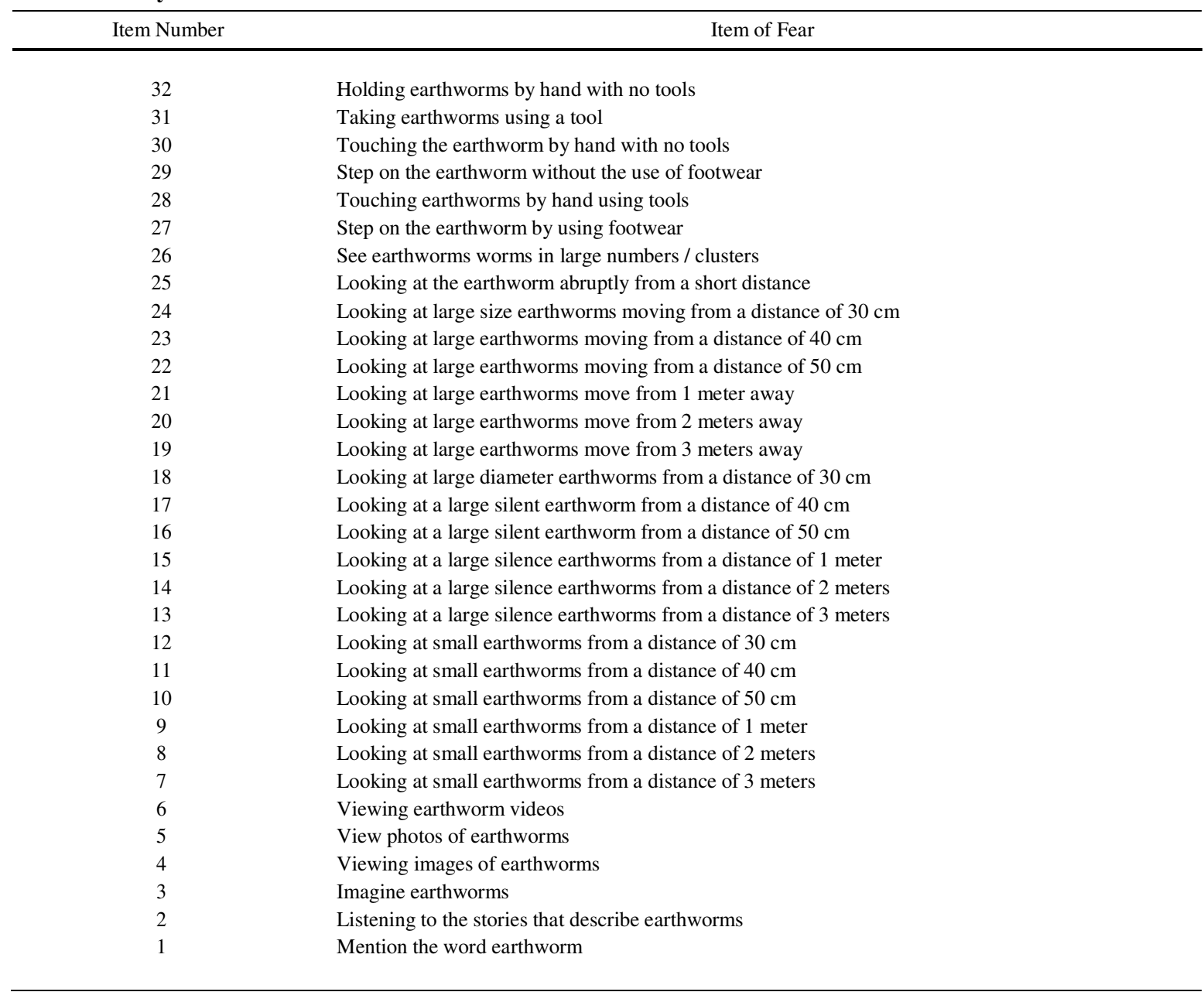

In the third session, pictures and video of earthworms were shown to the client. She said that she felt a bit anxious and excited about facing this session because she needs to see real earthworm photos and videos and not just two-dimensional images. This session began with a review of the activities conducted in the previous session. The subject was then asked to describe what she felt in the previous session. Before beginning the exposure session, the subject was given with progressive relaxation first. Although relaxation has been regarded as an inessential component of exposurebased therapy (Barlow, 2002), it enhances both the motivation and acceptability of the client for the treatment and helps in firming commitment to the treatment. In this session, she was shown with photographs of earthworm, with three-dimensional shape and original color, by using a laptop screen. This session made the client anxious, and she sat away from the screen. She tried to regulate her rapid breath, and her hands were moving. Moreover, several photos were shown to 
the subject during the session. The client was then given a break so she can regulate her breathing and become more calm and relaxed. After the session of seeing the earthworm photo for about 30 minutes, changes in the scale were reviewed based on what was felt by the client. The SUDS score decreased from 20 to 0 . The treatment was continued to the next level, where the client will watch a video of earthworms. During video viewing, the client said that at this time, she felt she can control her fear compared when she was undergoing the treatment. The SUDS score decreased to 25 upon viewing earthworms and further decreased to 0 after relaxation and exposure.

In the fourth session, the exposure was started from item number 7 to item number 12 . The client was asked to see the small worm placed from a distance of $3 \mathrm{~m}$ to a closer distance of $30 \mathrm{~cm}$. The client was able to gradually move closer to the small earthworm until she reached the closest distance of $30 \mathrm{~cm}$. The subject even attempted to lift the worm on the paper forward to $30 \mathrm{~cm}$. After this session, the subject said that she managed to be in the closest distance to see earthworms compared with that before the treatment. The subject felt that she can control her anxiety when she sees a small earthworm from a distance that she thinks is close enough. The SUDS form was given at the end of the session to determine changes in the score.

In this fifth session, the treatment was started from item number 13 to item number 25 . The client was asked to see big worms from distance of $3 \mathrm{~m}$ to $30 \mathrm{~cm}$. The earthworms shown to the client were silent or moving. In this session, the client seemed to gain positive development. She approached a large worm from a close range, which she thought was the closest distance between herself and the large earthworm. Although she moved away several times and her breath was rapid, she controlled her fear quite well. After this session, the client was again shown its development in handling her phobia to earthworm through the hierarchy table. The client was already in item 25 in the hierarchy. The SUDS form was given at the end of this session to determine changes in the client's scores.

In the sixth session, exposure was started from item number 26 to item number 32. Relaxation was given at the beginning of the session to allow the client to relax and be calm. A review of what activities were conducted in the previous session was conducted to see the treatment progress of the client. Each step was required to be performed by the client. The implementation of the stages was enhanced if the scores obtained at each stage reach a positive change. Earthworms were placed on a table located in front of the client. She was asked to see a large number of worms in front of her. She also asked to touch the earthworm by using her hands. In the next stage, she was asked to take the earthworm in front of her by using a pencil. In the last item, she was asked to hold and take the earthworm by using her hand without a tool. However, she said she was not willing to do the last stage and felt that she already had enough. Based on the client's statement, the treatment was terminated up to item 31. The decreasing SUDS score becomes the basis for continuing or terminating the session to achieve the designed objectives (Buchanan \& Houlihan, 2008). At the end of the session, the SUDS table was shown to the client to see her treatment progress.

\section{Results}

Exposure therapy not only involves a cognitive approach but also facilitates clients to communicate their fears in the hope that they will learn about their capabilities and how will they use them in everyday life when confronted with such fears (Popescu, 2012). In the present work, 
treatment of the client involves exposing her to earthworm, which is the client's phobia, in each given session. The exposure to earthworms begins with the use of images and videos to show earthworms in their actual forms. Barlow (2002) pointed out that the use of videos as part of exposure therapy is relatively common. In the treatment given to the client, the provision of a video of worms at the beginning of the session is considered effective and sufficient to see the anxiety of the client and determine how long the session will be performed. Fryrear and Werner (1970) used the combination of modeling (via video) and progressive relaxation to treat a 19year-old female. She was much improved after the treatment conducted in seven sessions. In each exposure session, progressive relaxation was also given to the client at the beginning of the treatment to provide a relaxed effect on her; the relaxation also made the client feel calm and motivated to carry out the series of treatments. At the end of each session, the treatment progress of the client was measured based on changes in her SUDS scores. Based on the evaluation of the SUDS scores at the end of the sessions, the treatment with in vivo exposure can effectively overcome the earthworm phobia experienced by the client. At the beginning of the treatment session, the client appeared very uncomfortable around earthworms. At the end of the session, the client was able to do one of the items in the hierarchy, that is, she took the earthworm by using a tool. This step is in accordance with the purpose of the treatment to allow the client to face her fears of earthworms and eliminate her avoidance behavior.

Table 1 shows the overview of pre-test SUDS scores related to client fears of earthworms. SUDS measurements were performed on the client at the end of each session to assess her treatment progress. At the end of the second session, changes in the SUDS scale on item numbers 1 to 4 were measured. The change in the scale seemed quite positive and significant. The scale on each item changes to 0 , which indicates the absence of anxiety of the client for that item. The scale ranges from 0 (indicating no anxiety at all) to 100 (indicating the most severe anxiety) (Wolpe, 1973). In addition to items 1 to 4, positive and significant changes were found on items 5 to 16 . The score obtained on item 5 to 16 at the end of the session is 0 , which means that the fear has been successfully overcome by the client. On item 31, the scale appeared positive; the pre-test SUDS score was 95, which positively changed to 30 at the end of the session. The treatment was terminated on item 31 because the client asserted that the result was already sufficient; as such, the scale on the last item was not changed.

The client also showed positive qualitative changes. Before starting the first session, the client said that she did not want to overcome her phobia. At the beginning of the session, the client shouted a few times when she was exposed to earthworms during the treatment. However, in the middle course of the treatment, the client seemed able to control her anxiety when exposed to earthworms. The client said that although the therapy session using exposure technique felt quite heavy for her, she had a strong motivation to overcome her phobia. At the end of the final therapy session, the client said that she felt happy because of the result. She did not think that she could overcome her fear of earthworms. The statements disclosed by the client during the course of the treatment indicated that she experienced a positive change and was satisfied with the treatment results. The client also stated that she can control her anxiety when exposed to earthworms.

One year after the implementation of the treatment, the client was followed up by interview. The client stated that the treatment has remained effective up to the present. She said that she can 
control her anxiety when exposed to earthworms and does not hysterically respond when she is under a phobic situation.

\section{Table 3}

Initial SUDS Score and its Changes after the Treatment: Session 2 (items 1-4), session 3 (items 5-6), session 4 (items 7 12), session 5 (items 13-25), and session 6 (items 26-32).

\begin{tabular}{ccc}
\hline Item & SUDS Score & SUDS Change \\
\hline & 0 & \\
Item 1 & 10 & 0 \\
Item 2 & 15 & 0 \\
Item 3 & 18 & 0 \\
Item 4 & 20 & 0 \\
Item 5 & 25 & 0 \\
Item 6 & 28 & 0 \\
Item 7 & 29 & 0 \\
Item 8 & 30 & 0 \\
Item 9 & 31 & 0 \\
Item 10 & 32 & 0 \\
Item 11 & 33 & 0 \\
Item 12 & 34 & 0 \\
Item 13 & 35 & 0 \\
Item 14 & 36 & 0 \\
Item 15 & 37 & 0 \\
Item 16 & 38 & 5 \\
Item 17 & 39 & 5 \\
Item 18 & 40 & 5 \\
Item 19 & 41 & 5 \\
Item 20 & 42 & 5 \\
Item 21 & 45 & 7 \\
Item 22 & 48 & 7 \\
Item 23 & 50 \\
Item 24 & 50 \\
Item 25 & 55 & 7 \\
Item 26 & 60 & 10 \\
Item 27 & 65 & 10 \\
Item 28 & 78 & 8 \\
Item 29 & 85 & 10 \\
Item 30 & 90 & 15 \\
Item 31 & 100 & 18 \\
Item 32 & & 100 \\
& & \\
\hline
\end{tabular}

\section{Discussion}

The use of exposure techniques coupled with progressive relaxation showed a positive improvement in decreasing the anxiety of clients with specific phobias. Based on the positive direction of changes in the SUDS scale, the treatment could be effective. These results support those of a previous study conducted by Buchanan dan Houlihan (2008) on the use of in vivo exposure and relaxation for treating phobia against earthworms. In the present study, the hypothesis tested is that both in vivo exposure combined with applied relaxation would lead to significant improvements in the patient (Öst, Lindahl, Sterner, \& Jerremalm, 1983). Relaxation training was employed as a non-threatening treatment strategy for patients to help strengthten therapeutic relationship, help reduce anxiety about the treatment, and build self-efficacy for coping with anxiety (Pagoto, Kozak, Spates, \& Spring, 2006). In our work, progressive relaxation given to the client at the beginning of each session helped her to become calm and relaxed prior to exposure sessions. One of the factors affecting the success of the treatment is the motivation of the client to overcome her phobia. Motivation allows the client to undergo each session with enthusiasm and willingness to take the steps instructed by the researcher. Based on the statement of the client in the beginning of session, she was highly motivated to follow the treatment because 
she needs to overcome her fear of earthworms. Moreover, the early video shown to her became a good input to view her anxiety so appropriate treatments can be administered. Positive changes in the client behavior were detected at the end of the exposure session. The client became calm and controlled her anxiety when she saw earthworms in front of her.

Future studies should conduct complete measurement of the anxiety scale to provide detailed information about the results of the treatment. Moreover, during follow up, the last SUDS score has been achieved by the client should also be shown, and the client should also be asked to give a new score of the hierarchy to determine if the effectiveness of the treatment persists for long periods of time. Overall, based on the quantitative and qualitative results, the implementation of systematic desensitization combined with exposure methods can effectively overcome phobia against earthworms.

\section{Reference}

American Psychiatric Association. (2000). Diagnostic and Statistical Manual of Mental Disorder. 4th ed. Text Revision. Washington DC.

Barlow, D. H. (2002). Anxiety and its disorder. 2nd ed. New York: Guilford.

Buchanan, J. A., \& Houlihan, D. (2008). The Use of In vivo Desensitization for the Treatment of a Specific Phobia of Earthworms. Clinical Case Studies, Vol. 7 No. 1, 12-24.

Davis, T., Ollendick, T., \& Öst, L. (2012). Intensive One-Session Treatment of Specific Phobia. Springer: New York.

Dolbier, L. C., \& Rush, T. E. (2012). Efficacy of Abbreviated Progressive Muscle Relaxation in a High-Stress College Sample. International Journal of Stress Management. Vol. 19, No. 1, 48-68.

Feist, J., Feist, G. J., \& Roberts, T.A. (2013). Theories of personality (8th ed.). New York: The McGraw-Hill Companies.

Foa, E. B., \& Kozak, M. J. (1986). Emotional processing of fear: Exposure to corrective information. Psychological Bulletin, 2035.

Fryrear, J. L., \& Werner, S. (1970). Treatment of a phobia by use of a videotaped modeling procedure: a case study. B\&ax. Ther. $1,391-394$

Hall, C.S., Lindzey, G., Loehlin, J. C., \& Manosevitz, M. (1985). Introduction to theory of personality. New York : Wiley

Kessler, R. C., Chiu, W. T., Demler, O., \& Walters, E. E. (2005). Prevalence, severity, and comorbidity of 12-month DSM-IV disorders in the national comorbidity survey replication. Archives of General Psychiatry, 62, 617-627.

King, N. J., Ollendick, T. H., \& Gullone, E. (1990). Desensitization of childhood fears and phobias: Psychophysiological analyses. Behaviour Change, 7, 66-75.

Kozak, M. J., \& Montgomery, G. K. (1981). Multimodal behavioral treatment of recurrent injury-scene-elicitaed-fainting (vasodepressor syncope). Behaviour Psychotherapy. 9, 316-321.

Kring, A. M., Johnson, S. L., Davison, G., \& Neale, J. (2013). Abnormal Psychology. International Student Version. 12th ed. Singapore. Wiley \& Sons, Inc.

Muris, P., \& Merckelbach, H. (2012). Specific Phobia: Phenomenology, Epidemology, and Etiology. Autism and Child Psychopatology Series. Springer

Öst, L. G., Lindahl, I. L., Sterner, U., \& Jerremalm, A. (1983). Exposure In Vivo Vs Applied Relaxation in The Treatment of Blood Phobia. Behaviour Thererapy. Vol. 22. No. 3, pp 205-216. Pergamon Press Ltd.

Pagoto, S. L., Kozak, A. T., Spates, C. R., Spring, B. (2006). Systematic Desensitization for Older Woman with a Severe Specific Phobia: An Application of Evidenced-Based Practice. Clinical Gerontologist, Vol. 30(1). The Hawort Press, Inc.

Popescu, B. (2012). Exposure Therapy for Phobias. Europe's Journal of psychology. Vol. 9 (2), 406-408).

Scott, M. J., \& Stradling, S. G. (1997). Client compliance with exposure treatments for posttraumatic stress disorder. Jounal Trauma Stress. 10 (3), 523-526.

Silverman, W. K., \& Kearney, C. A. (1992). Listening to our clinical partners: Informing researchers about children's fear and phobias. Journal of Behaviour Therapy and Experimental Psychiatry. 23, 71-76.

Wolpe, J. (1973). The practice of behavior therapy. New York: Pergamon.

Zayfert, C. (2000). Implementation of empirically supported treatment for PTSD: Obstacles and innovations. Behav iour Therapy. 23, 161-168. 